\title{
Investigation of electron density profile in the lower ionosphere by SRP-4 rocket experiment
}

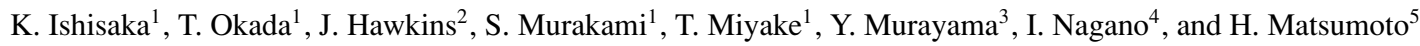 \\ ${ }^{1}$ Toyama Prefectural University, Kosugi, Toyama 939-0398, Japan \\ ${ }^{2}$ University of Alaska Fairbanks, Fairbanks, Alaska 99775-5919, U.S.A \\ ${ }^{3}$ National Institute of Information and Communications Technology, Koganei, Tokyo 184-8795, Japan \\ ${ }^{4}$ Kanazawa University, Kanazawa, Ishikawa 920-1192, Japan \\ ${ }^{5}$ Research Institute for Sustainable Humanosphere, Kyoto University, Uji, Kyoto 611-0011, Japan
}

(Received October 23, 2003; Revised July 4, 2005; Accepted July 4, 2005)

\begin{abstract}
The SRP-4 rocket was launched at 12:07 LT on 18 March 2002. The objective of this rocket experiment is the investigation of the electron density profile in the high-latitude D-region of the ionosphere at noon. The Low frequency and Medium frequency band radio Receiver (LMR) and the DC Probe System (DPS) were installed on-board the rocket to estimate the D-region electron density. The LMR measured the intensities of radio waves received from ground-based stations operating at $257 \mathrm{kHz}, 660 \mathrm{kHz}$ and $820 \mathrm{kHz}$, respectively. The DPS measured the electron current and the positive ion current using the biased electrodes. The electron density profile at altitudes below $90 \mathrm{~km}$ was estimated from the measured absorption of these radio waves. It was found that the electron density began to increase at the altitude of $52 \mathrm{~km}$ and was larger than that estimated by the International Reference Ionosphere model at altitudes from $74 \mathrm{~km}$ to $89 \mathrm{~km}$.
\end{abstract}

Key words: Propagation characteristic of radio wave, electron density, ionosphere, rocket experiment, full wave method.

\section{Introduction}

The quality of many radio communication systems, navigation systems, and broadcasting services depends on the radio wave propagation characteristics in the lower ionosphere. The electron number density profile in the lower ionosphere is important because the high electron-neutral particle collision frequencies affects the radio wave absorption in the ionosphere. X-rays, Lyman- $\alpha$ and cosmic-ray particles are the dominant ionization source at altitudes below $90 \mathrm{~km}$. The dominant ions can recombine with electrons. At these low altitudes, the electrons can also attach themselves to neutrals to form negative ions (Hunsucker and Hargreaves, 2003; Kivelson and Russell, 1995). The standard International Reference Ionosphere (IRI) model gives the estimated electron density profile based on available measurements, but insufficient measurements have been accumulated to yield reliable estimates below $65 \mathrm{~km}$ (Bilitza, 1998; Bilitza, 2001; Friedrich and Torkar, 2001).

The Alaska Student Rocket Project 4 (SRP-4) experiment was carried out to investigate the electron density profile below $90 \mathrm{~km}$. The SRP-4 rocket was launched at Poker Flat Research Range (65.1N, 212.5E, in the geographical coordinate system) at 12:07 LT on March 18 2002. A radio receiver and the DC current probe on-board the SRP4 rocket payload were used to estimate the electron density profile of lower ionosphere have observed the propagation

Copyright (C) The Society of Geomagnetism and Earth, Planetary and Space Sciences (SGEPSS); The Seismological Society of Japan; The Volcanological Society of Japan; The Geodetic Society of Japan; The Japanese Society for Planetary Sciences; TERRAPUB. characteristics of radio waves and the DC current in the lower ionosphere using the method previously described by some of the authors (Okada and Nagano, 1990; Okada et al., 1997; Nagano and Okada, 2000).

In this paper we show that the electron density profile in the ionosphere below $90 \mathrm{~km}$ can be estimated by comparing these experimental results with the propagation characteristics calculated by the full wave method.

\section{Experimental Instruments On-board the SRP- 4 Rocket}

The scientific instruments on-board SRP-4 rocket consist of the LF and MF band radio Receiver (LMR), the DC Probe System (DPS) and the magnetometer (Ishisaka et al., 2002). Figure 1 shows the location of these scientific instruments on-board the SRP-4 rocket. In this study, we use the data measured by the LMR and DPS in order to estimate the electron density profile of lower ionosphere.

The LMR measures the received radio wave intensities from three navigation and broadcast stations near Fairbanks, Alaska at frequencies of $257 \mathrm{kHz}, 660 \mathrm{kHz}$ and 820 $\mathrm{kHz}$, respectively. The LMR consists of a loop antenna, a pre-amplifier and a detector circuit. The loop antenna is mounted in the nose cone as shown in Fig. 1. The nose cone is designed to be transparent to LF and MF band radio waves because it is not deployed during the flight. Therefore, the LMR can measure the relative attenuation of radio waves from the ground up to the ionosphere. Figure 2 shows the electrical block diagram of the LMR. The waves of 257 $\mathrm{kHz}, 660 \mathrm{kHz}$ and $820 \mathrm{kHz}$ are received by the trapezoidshaped loop antenna (two parallel bases $95 \mathrm{~mm}$ and 290 


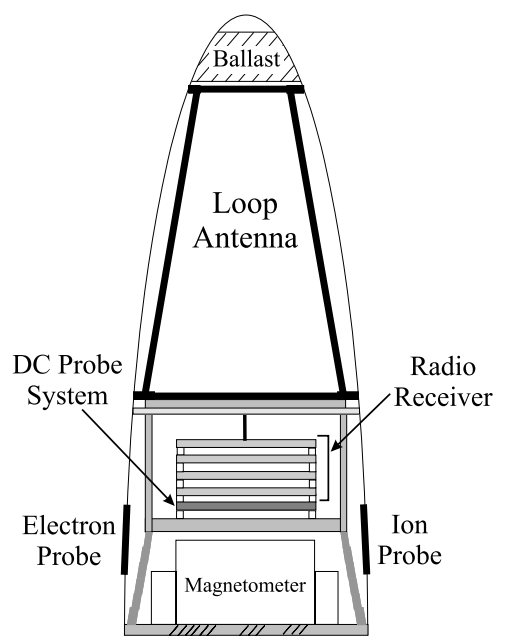

Fig. 1. Location of scientific instrument onboard SRP-4 rocket. The loop antenna is set up in the nose cone which is transparent to MF radio waves. Two electrodes with positive and negative biases are located on the rocket nose cone at antenna nulls to measure the relative density of electrons and ions, respectively.

$\mathrm{mm}$, height $920 \mathrm{~mm}$, area $0.1771 \mathrm{~m}^{2}, 10$ turns). The loop antenna is connected to wide-band $(200-1000 \mathrm{kHz})$ preamplifier, which consists of a transformer and a low-noise amplifier. The $257 \mathrm{kHz}, 660 \mathrm{kHz}$ and $820 \mathrm{kHz}$ waves are each selected from the output of the pre-amplifier by a filter tuned to each frequency with a bandwidth of $2 \mathrm{kHz}$, and then super-heterodyned to an intermediate frequency of $455 \mathrm{kHz}$. The $455 \mathrm{kHz}$ signal is envelope-detected a digitized with 8-bit accuracy. The detection threshold of magnetic field intensity and dynamic range are given as 1.55 $\mathrm{fT} / \sqrt{\mathrm{Hz}}, 61 \mathrm{~dB}$ at $257 \mathrm{kHz}, 1.90 \mathrm{fT} / \sqrt{\mathrm{Hz}}, 63 \mathrm{~dB}$ at 660 $\mathrm{kHz}$ and $2.72 \mathrm{fT} / \sqrt{\mathrm{Hz}}, 61 \mathrm{~dB}$ at $820 \mathrm{kHz}$.

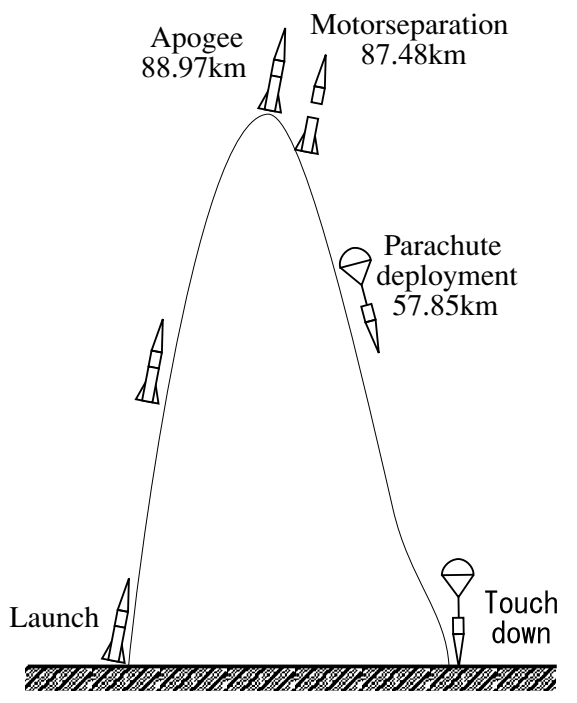

Fig. 3. Illustration of the trajectory of the SRP-4 rocket flight. The rocket reached an apogee of altitude $88.97 \mathrm{~km}$ at $160 \mathrm{sec}$.

The DPS collects electrons and positive ions of the plasma around the rocket. Each of the electrodes of the DPS is made of a gold-plated copper sheet with an area of $50 \mathrm{~mm} \times 100 \mathrm{~mm}$ and thickness of $0.03 \mathrm{~mm}$. The electrodes are mounted on the nose cone as shown in Fig. 1. One of the electrodes is positively biased to $+5 \mathrm{~V}$ with respect to the rocket body to collect the electrons around the rocket. The other electrode is negatively biased to $-5 \mathrm{~V}$ to collect the positive ions. However, we cannot obtain absolute electron density from the measured current because the conversion factor from the electrode current to the ambient electron density is unknown.

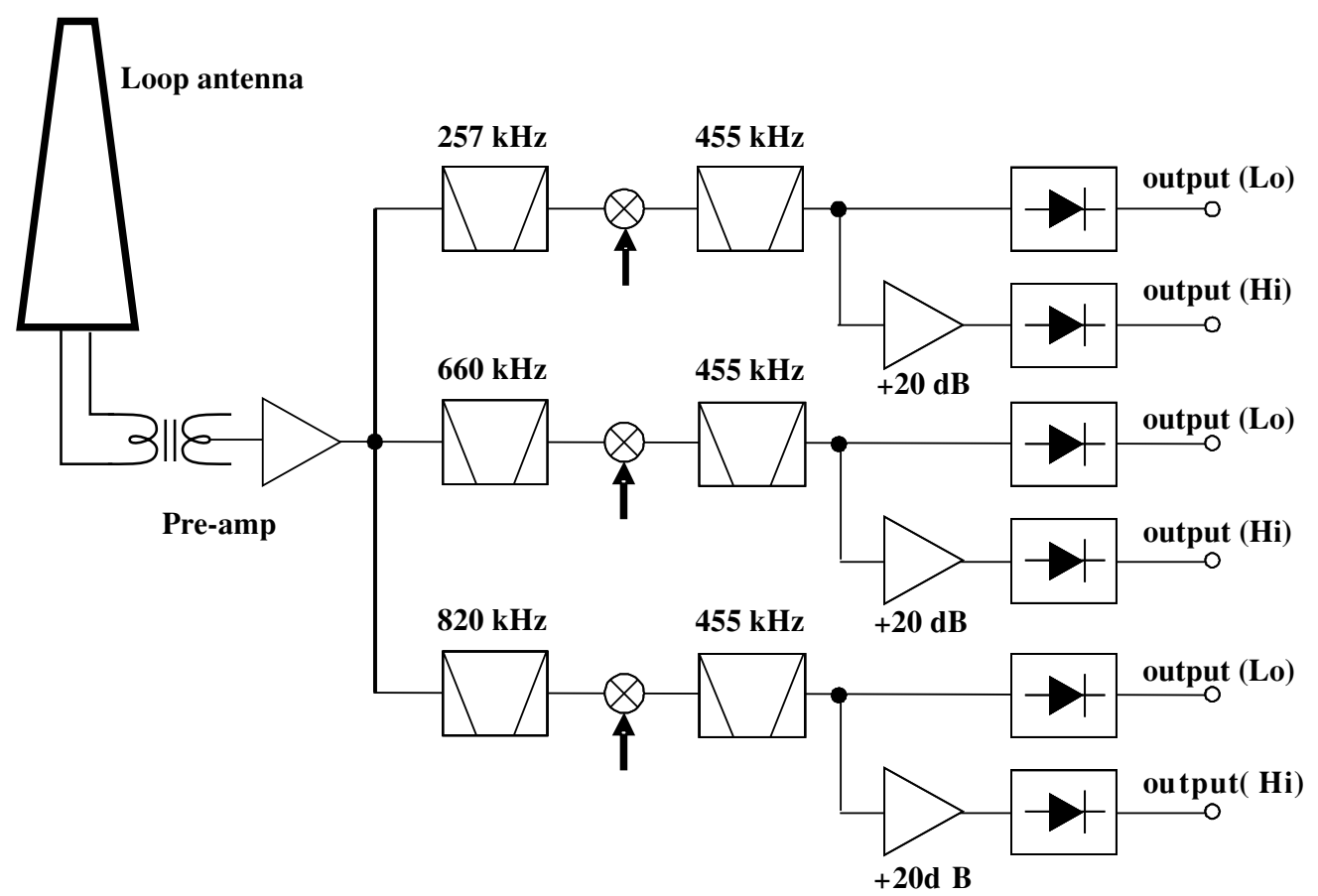

Fig. 2. A electrical block diagram of the LF and MF band radio wave Receiver (LMR) onboard the SRP-4 rocket. 
(a) $257 \mathrm{kHz}$

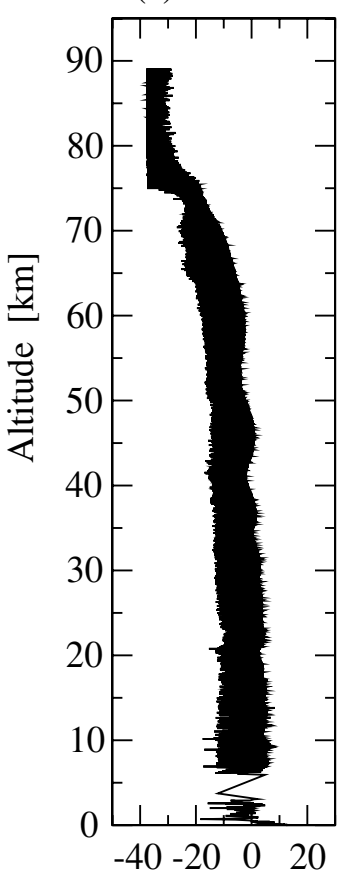

(b) $660 \mathrm{kHz}$

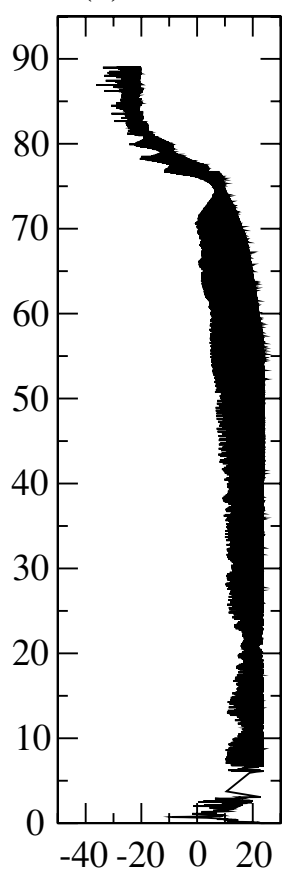

(c) $820 \mathrm{kHz}$

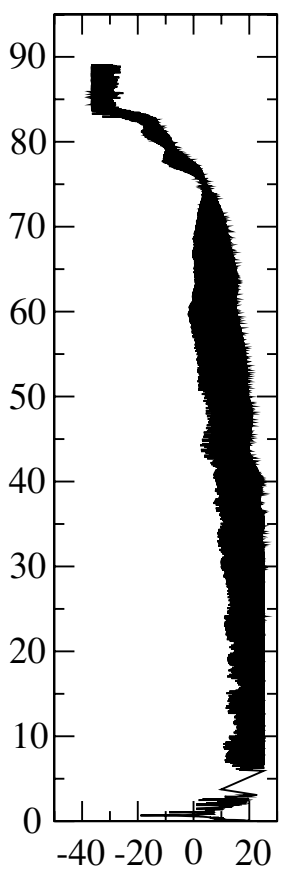

Field intensity $[\mathrm{dB} \mu \mathrm{A} / \mathrm{m}]$ (d) DC probe

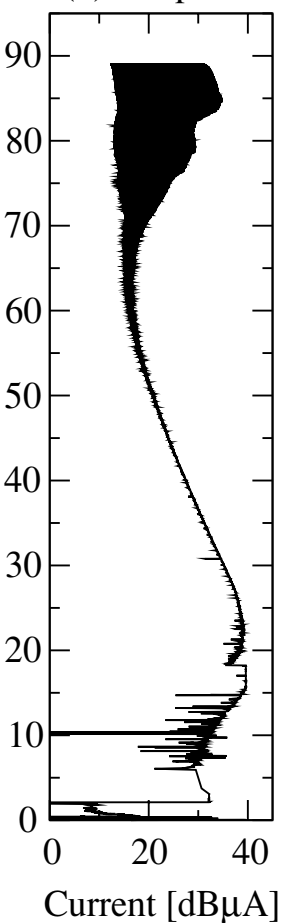

Fig. 4. Measurement results of three MF radio wave intensities, (a) $257 \mathrm{kHz}$, (b) $660 \mathrm{kHz}$, and (c) $820 \mathrm{kHz}$, and (d) the electron current measured by the DC probe system during the ascent flight.

\section{Observation Results}

The SRP-4 rocket was launched from the Poker Flat Research Range at 12:07 LT on March 18, 2002. Figure 3 shows the trajectory of the rocket. The rocket reached an apogee of $88.97 \mathrm{~km}$ at $142 \mathrm{sec}$ after firing. The payload separated from the rocket motor at $160 \mathrm{sec}(87.48 \mathrm{~km})$ and the parachute was deployed at $223 \mathrm{sec}(57.85 \mathrm{~km})$.

\subsection{LF and MF band radio wave observation}

Figure 4 shows received strength of waves at (a) $257 \mathrm{kHz}$, (b) $660 \mathrm{kHz}$ and (c) $820 \mathrm{kHz}$ that were transmitted from navigation and broadcast stations near Fairbanks, Alaska during the ascent. The vertical axis indicates the altitude of the rocket, while the horizontal axis indicates the LF and MF radio wave intensity in unit of $\mathrm{dB} \mu \mathrm{A} / \mathrm{m}(0 \mathrm{~dB} \mu \mathrm{A} / \mathrm{m}$ $=1 \mu \mathrm{A} / \mathrm{m})$. The $257 \mathrm{kHz}, 660 \mathrm{kHz}$ and $820 \mathrm{kHz}$ waves were modulated with an intensity variation of about $20 \mathrm{~dB}$ at altitudes up to $73 \mathrm{~km}$. The intensity modulation is due to the directivity of the loop antenna and the rotation of the loop antenna plane. The modulation frequency is 11.4 $\mathrm{Hz}$, which is twice the rocket spinning frequency of $5.7 \mathrm{~Hz}$. The intensity of the $257 \mathrm{kHz}$ wave decreases gradually with increasing altitude until it reaches the system noise level of the receiver at $75 \mathrm{~km}$. The intensity of $660 \mathrm{kHz}$ wave decreases steeply in the altitude range from $73 \mathrm{~km}$ up to $81 \mathrm{~km}$ and the intensity of $820 \mathrm{kHz}$ wave decreases steeply from $73 \mathrm{~km}$ up to $84 \mathrm{~km}$. These attenuations in the wave intensity are due to collisions between the electrons and the neutral molecules in the lower ionosphere. The $660 \mathrm{kHz}$ and the $820 \mathrm{kHz}$ wave intensities are approximately equal to the system noise level of the receiver at $81 \mathrm{~km}$ and 84 $\mathrm{km}$, respectively.

\subsection{DC probe current measurement}

Figure 4(d) shows the measured profile of electron current at altitudes below $89 \mathrm{~km}$ during the ascent. The horizontal axis is the electron current in units of $\mathrm{dB} \mu \mathrm{A}(0 \mathrm{~dB} \mu \mathrm{A}$ $=1 \mu \mathrm{A})$, and the vertical axis is the altitude. The electron current increases up to a maximum at $23 \mathrm{~km}$ and then decreases gradually up to about $60 \mathrm{~km}$. The electron current measurements in this experiment agree with the result reported by Rose and Widdle (1972) for altitudes below 50 $\mathrm{km}$. However, the source of this high electron density at these low altiutdes is not known at present. The electron current at the altitude range from $50 \mathrm{~km}$ to $89 \mathrm{~km}$ was modulated at $5.7 \mathrm{~Hz}$ by the spin frequency of the rocket. The electron current increases steeply up to $89 \mathrm{~km}$ and two current peaks are found at altitudes of $76 \mathrm{~km}$ and $83 \mathrm{~km}$.

\section{Estimation of Electron Density Profile using the Full Wave Method}

We have estimated the electron density profile in the lower ionosphere using the measured propagation characteristics of the three waves shown in Figure 4(a)-(c) and the full wave method. The full wave method requires the initial electron density profile, the collision frequency profile, the gyro-frequency, the azimuthal angle of geomagnetic field, the incident angle of each radio waves and so on (Nagano and Okada, 2000). The incident angle of the radio waves from the transmitter to the lower ionosphere significantly affects the intensity of the radio wave in the ionosphere. The incident angles of the $257 \mathrm{kHz}, 660 \mathrm{kHz}$ and $820 \mathrm{kHz}$ radio waves are $34.5^{\circ}, 38.2^{\circ}$ and $34.5^{\circ}$, respectively. The procedure used to estimate the collision frequency is described in Section 4.1. To estimate the actual electron density profile, 


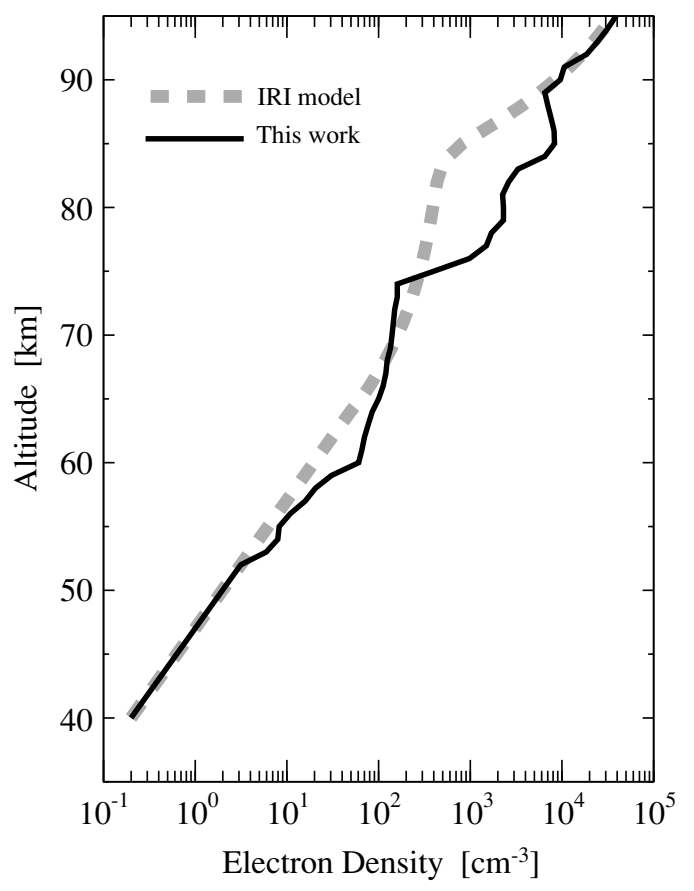

Fig. 5. Electron density profile from $40 \mathrm{~km}$ to $95 \mathrm{~km}$ for the full wave method. The broken line is the electron density profile obtained by the IRI model. The solid line shows the modified electron density profile.

we first calculated the intensity profile of radio wave using an initial electron density, and then modify the electron density profile until the altitude variation of the calculated absorption fits best to the observed one.

\subsection{Collision frequency in use the full wave method}

The collision frequency in the lower ionosphere is proportional to the atmospheric pressure. The collision frequency $v$ between the neutral molecules and electrons can be expressed by the equation $v=K_{\mathrm{m}} \times 10^{5} \mathrm{P}$, where $P[\mathrm{~Pa}]$ is the atmospheric pressure and $K_{\mathrm{m}}=6.4$ is the collision proportional factor (Gregory and Manson, 1967). This equation is an empirical expression deduced from the then best available laboratory measurements of momentum transfer cross-sections for collisions between electrons and neutral molecules. Values of $P$ are obtained from a suitable atmospheric pressure model such as the CIRA (COSPAR International Reference Atmosphere) model (Fleming et al., 1990).

\subsection{Estimation of electron density profile in the lower ionosphere}

We obtain an initial estimate of the electron density profile in the lower ionosphere using the IRI model. A linear extrapolation is used to extend this estimate to altitudes from $40 \mathrm{~km}$ to $65 \mathrm{~km}$ where the IRI model is not defined. This initial electron density profile extended over the altitude of $40 \mathrm{~km}$ is shown by the broken line in Fig. 5 .

Figure 6 shows three radio wave propagation profiles at frequencies of (a) $257 \mathrm{kHz}$, (b) $660 \mathrm{kHz}$, and (c) $820 \mathrm{kHz}$ calculated by the full wave method using (d) the electron density profile from the IRI model. The black line is the radio wave intensity calculated by the full wave method, and the grey line is the radio wave intensity measured by the LMR. The vertical axis is the altitude and the horizotal axis is a relative value of radio wave intensity normalized to $0 \mathrm{~dB}$ at $40 \mathrm{~km}$. The three radio wave intensities calculated (a) $257 \mathrm{kHz}$

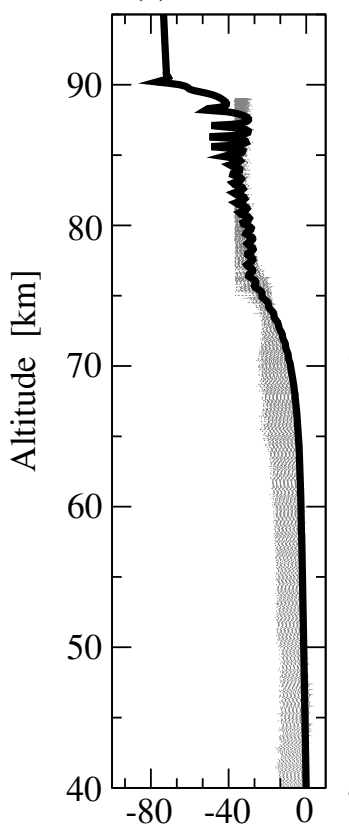

(b) $660 \mathrm{kHz}$

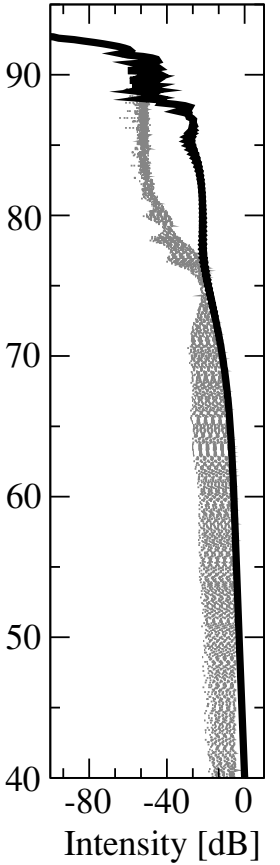

(c) $820 \mathrm{kHz}$

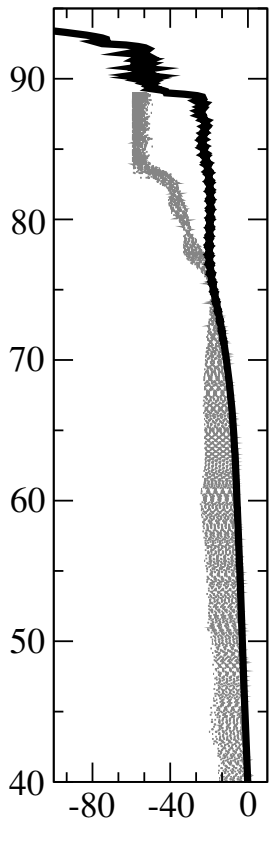

(d) Electron density

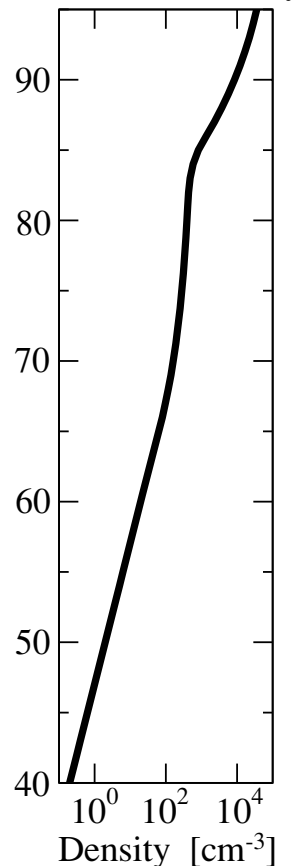

Fig. 6. Three radio wave propagation profiles, (a) $257 \mathrm{kHz}$, (b) $660 \mathrm{kHz}$, and (c) $820 \mathrm{kHz}$, calculated by full wave method using (d) the electron density profile of the IRI model. The vertical axis is the altitude and the horizotal axis of the radio wave propagation is a relative value of wave intensity that is normalized to $0 \mathrm{~dB}$ at $40 \mathrm{~km}$. The black line denotes the radio wave intensity calculated by the full wave method. For comparison, the observed radio wave intensity is denoted by the gray line. 
(a) $257 \mathrm{kHz}$

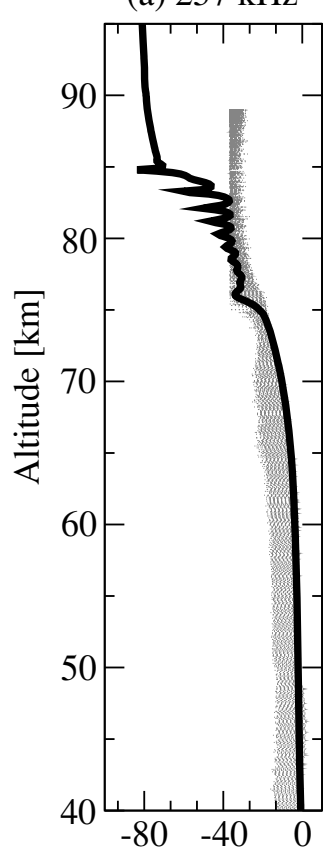

(b) $660 \mathrm{kHz}$

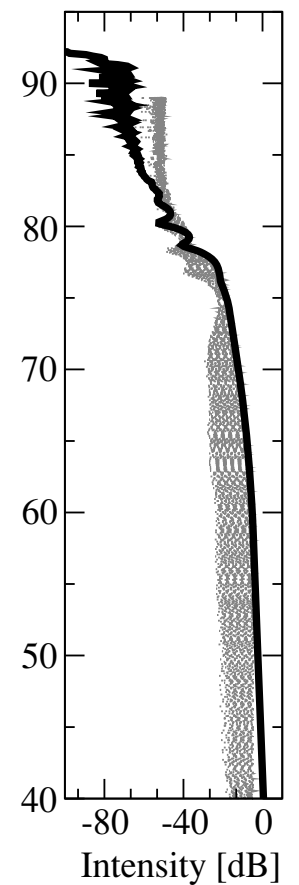

(c) $820 \mathrm{kHz}$

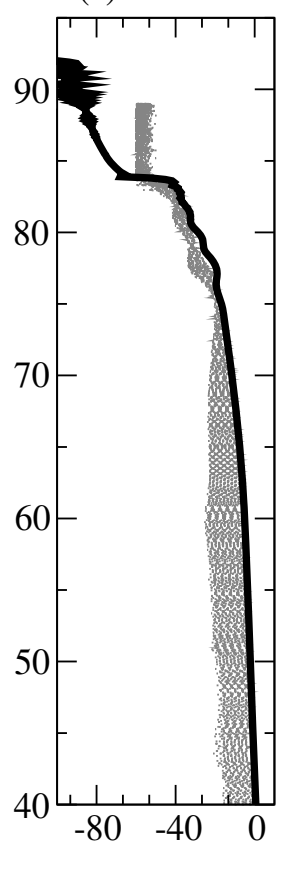

(d) Electron density

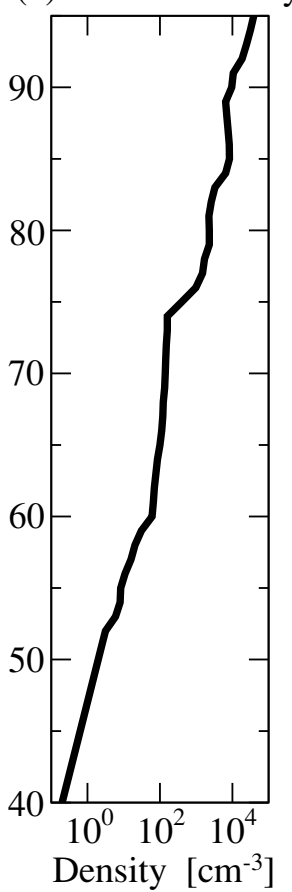

Fig. 7. Three radio wave propagation profiles, (a) $257 \mathrm{kHz}$, (b) $660 \mathrm{kHz}$, and (c) $820 \mathrm{kHz}$, calculated by full wave method using (d) the modified electron density profile.

by the full wave method agree with the observed intensities at the altitudes from $40 \mathrm{~km}$ to $74 \mathrm{~km}$, but the $660 \mathrm{kHz}$ and $820 \mathrm{kHz}$ radio wave intensities calculated by the full wave method are clearly different from the observed values above $74 \mathrm{~km}$, as shown in Figs. 6(b) and (c).

We then modify the electron density profile to be proportional to the electron current measured by the DPS. The measured electron current begin to increase above $52 \mathrm{~km}$ with two peaks at the altitude of $78 \mathrm{~km}$ and $84 \mathrm{~km}$, as shown in Fig. 4(d). This yields the modified electron density profile shown by the solid line in Fig. 5. Figure 7 shows intensities of three radio waves (a)-(c) calculated by using the modified electron density profile (d). Good agreement is seen between the calculated wave intensity and the measured wave intensity, i.e., the wave intensity decrease with increasing the altitude up to about $80 \mathrm{~km}$, and the $257 \mathrm{kHz}$ wave, $660 \mathrm{kHz}$ wave and $820 \mathrm{kHz}$ wave decrease to the system noise level of receiver at the altitude of $75 \mathrm{~km}, 81 \mathrm{~km}$ and $84 \mathrm{~km}$, respectively.

Though the altitude of total reflection was not measured in this rocket experiment, we estimated the electron density profile below $90 \mathrm{~km}$ using the characteristics of partial reflection of radio waves at altitudes from $50 \mathrm{~km}$ up to about $84 \mathrm{~km}$. We found that the electron density distribution at altitude up to $65 \mathrm{~km}$ affected the attenuation of radio waves at altitudes above $75 \mathrm{~km}$. The most probable electron density profile is indicated by the solid line in Fig. 5.

\section{Conclusion}

Measurements of LF and MF band radio wave intensities and the electron currents in the high latitude ionosphere have been carried out by the SRP-4 sounding rocket mission during the winter daytime in 2002. We measured electron

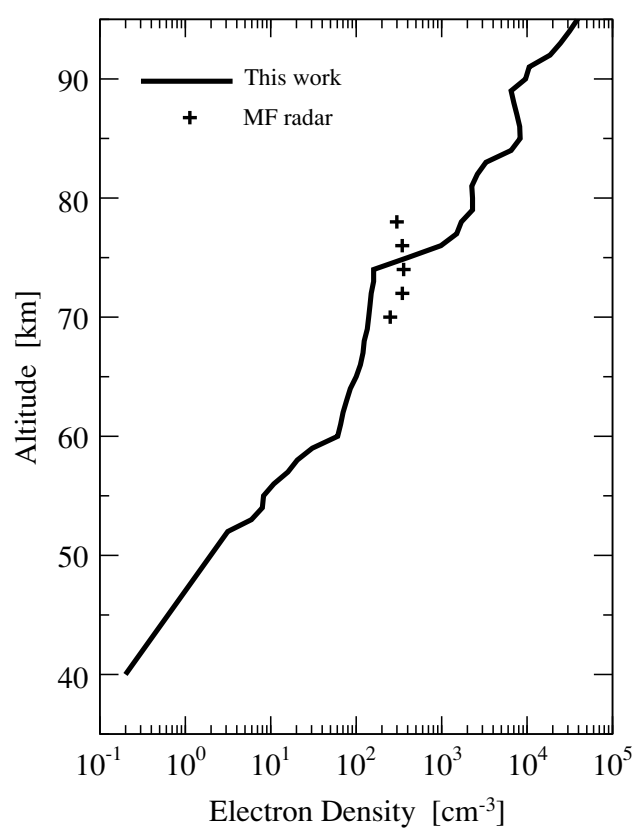

Fig. 8. Comparison of the electron density profiles estimated by the full wave method with that measured by the MF radar at Poker Flat. The vertical axis indicates the altitude and the horizontal axis indicates the electron density. The solid curve shows the most probable electron density profile estimated by the LF and MF radio wave intensities and the fullwave method. The plus marks "+" at $2 \mathrm{~km}$ intervals are the electron densities measured by the MF radar in the range $70 \mathrm{~km}$ to 78 $\mathrm{km}$ altitude.

currents at altitudes above $50 \mathrm{~km}$, which showed a rapid increase at approximately $70 \mathrm{~km}$. The intensities of three radio waves decreased with increasing altitude. In particular, we observed that the intensities of the $660 \mathrm{kHz}$ and 820 
$\mathrm{kHz}$ waves decreased suddenly at about $74 \mathrm{~km}$.

The electron density profile in the lower ionosphere was estimated from the LF and MF radio waves intensities using the full wave method. The observed radio wave intensity agreed with the intensity calculated using the full wave method with the modified electron density profile. We have estimated the most probable electron density profile below $90 \mathrm{~km}$ at high latitude from the SRP-4 rocket measurements. Consequently we found that the electron density in the region from $52 \mathrm{~km}$ to $68 \mathrm{~km}$ was required to obtain a good fit between the measured and calculated wave intensities.

The MF radar has been constructed by the National Institute of Information and Communications Technology (NICT) at the Poker Flat Research Range as a high latitude station. The MF radar is a powerful tool for studying the upper atmosphere, by measuring horizontal wind velocity and electron density. Electron density in the D-region of ionosphere can be estimated from the Differential Absorption Experiment (DAE) technique using the MF radar system (Murayama et al., 2000). We compared the electron density obtained by the SRP-4 rocket experiment with that estimated by the MF radar as shown in Fig. 8. It was clearly seen that the electron density calculated by the full wave method was different from that estimated by the MF radar at altitudes from $70 \mathrm{~km}$ to $80 \mathrm{~km}$. Murayama et al. (2000) indicated that the electron density profile by MF radar are highly variable even for a limited local time bin, ranging by a factor of $10 \sim 100$, because the ionosphere in the high latitude drastically changes due to aurora and other energetic particles and radiations.

In future work, we will investigate the estimation of electron density using the DAE technique. Then we will compare the electron density profile estimated by the MF radar with that estimated from the wave intensity of MF radar calculated by the full wave method, and improve the precision of electron density profile using the MF radar.

In the full wave method, we will discuss the collision frequency because it is very variable under the several condition such as the electron density, the altitude, the atmospheric pressure model, and so on. We will try to establish the estimation method of electron density in the lower ionosphere to the satisfaction of both the full wave method and DAE technique.
Acknowledgments. We appreciate the encouragement of Dr. S Akasofu of the Founding Director of the International Arctic Research Center in the SRP rocket experiment. The rocket experiments were carried out with the full cooperation of the member of Alaska Student Rocket Program. We wish to thank the member of Alaska Student Rocket Program for their continual advice and encouragement. We thank also the member of Tokai Student Rocket Project in this rocket experiment. The IRI model was obtained from the National Space Science Data Center (NSSDC). Funding and support for the SRP-4 sounding rocket mission were provided by NASA Wallops Flight Facility, NSROC, Poker Flat Research Range, and the Alaska Space Grant Program.

\section{References}

Bilitza, D., The E- and D-region in IRI, Adv. Space Res., 21, 871-874, 1998.

Bilitza, D., International reference ionosphere 2000, Radio Science, 36, 261-275, 2001.

Fleming, E. L., S. Chandra, J. J. Barnett, and M. Corney, Zonal mean temperature, pressure, zonal wind and geophysical height as a function of latitude, Adv. Space Res., 10, 11-59, 1990.

Friedrich, M. and K. M. Torkar, FIRI: A semiempirical model of the lower ionosphere, J. Geophys. Res., 106, 21,409-21,418, 2001.

Gregory, J. B. and A. H. Manson, Mesospheric electron number densities at $35^{\circ}$ latitude, J. Geophys. Res., 72, 1073-1080, 1967.

Hunsucker, R. D. and J. K. Hargreaves, The High-latitude Ionosphere and Its Effects on Radio Propagation, Cambridge University Press, United Kingdom, 617 pp, 2003.

Ishisaka, K., T. Okada, T. Nishio, J. G. Hawkins, S. Murakami, T. Miyake, I. Nagano, H. Matsumoto, and Y. Miyazawa, Measurement of the electron density profile in the lowest ionosphere by the Alaska rocket experiment, IEICE Trans. Commun., J85-B, 1147-1151, 2002 (in Japanese).

Kivelson, M. G. and C. T. Russell, Introduction to Space Physics, Cambridge University Press, United Kingdom, 568 pp, 1995.

Murayama, Y., K. Igarashi, D. D. Rice, B. J. Watkins, R. L. Collins, K. Mizutani, Y. Saito, and S. Kainuma, Medium frequency radars in Japan and Alaska for upper atmosphere observations, IEICE Trans. Commun., E83-B, 1996-2003, 2000.

Nagano, I. and T. Okada, Electron density profiles in the ionosphere Dregion estimated from MF radio wave absorption, Adv. Space Res., 25, $33-42,2000$.

Okada, T. and I. Nagano, Rocket experiment of VLF and MF radio wave measurement by using single loop anntena, IEICE Trans., E73, 237 244, 1990.

Okada, T., M. Mambo, T. Fukami, I. Nagano, and K. Okumura, Multipule thin layers of enhanced ionization in the ionospheric E-region derived from VLF wave measurements, J. Geomag. Geoelectr., 49, 69-76, 1997.

Rose, G. and H. U. Widdel, Results of concentration and mobility measurements for positively and negatively charged particles taken between 85 and $22 \mathrm{~km}$ in sounding rocket experiments, Radio Science, 7, 81-87, 1972 .

K. Ishisaka (e-mail: ishisaka@pu-toyama.ac.jp), T. Okada, J. Hawkins, S. Murakami, T. Miyake, Y. Murayama, I. Nagano, and H. Matsumoto 